\title{
Mechanical Properties and Microstructure Evolution of AA1100 Aluminum Sheet Processed by Accumulative Press Bonding Process
}

\author{
Amir Mostafapor ${ }^{1} \cdot$ Vahid Mohammadinia ${ }^{2}$
}

Received: 13 February 2016/Revised: 6 April 2016/Published online: 8 June 2016

(C) The Chinese Society for Metals and Springer-Verlag Berlin Heidelberg 2016

\begin{abstract}
Accumulative press bonding (APB) is a novel variant of severe plastic deformation processes, which is devised to produce materials with ultra-fine grain. In the present work, the mechanical properties and microstructural evolution of AA1100 alloy, which is produced by APB technique, were investigated. The study of the microstructure of AA1100 alloy was performed by optical microscopy. The results revealed that the grain size of the samples decreased to $950 \mathrm{~nm}$ after six passes of APB process. The yield strength of AA1100 alloy after six passes of the process increased up to $264 \mathrm{MPa}$, which is three times higher than that of the as-cast material $(89 \mathrm{MPa})$. After six passes, microhardness values of AA1100 alloy increased from 38 to $61 \mathrm{HV}$. Furthermore, the results showed that the behavior of variations in mechanical properties is in accordance with the microstructural changes and it can be justified by using the Hall-Patch equation. Moreover, the rise in the yield strength can be attributed to the reduction in the grain size leading to the strain hardening.
\end{abstract}

KEY WORDS: Severe plastic deformation; Accumulative press bonding; Mechanical properties; Metallurgical properties; AA1100 alloy

\section{Introduction}

Aluminum alloys are the most used nonferrous materials in industry that have extensive applications in home appliances, aerospace and automotive industries [1,2]. They play a crucial role in the field of modern engineering due to their superior mechanical and metallurgical properties such as good corrosion resistance, machinability, weldability and relatively low cost [3-5]. The investigations reported that alloying and age hardening are the best strategies to

Available online at http://link.springer.com/journal/40195

Vahid Mohammadinia

v.mohammadinia@gmail.com

1 Department of Mechanical Engineering, University of Tabriz, Tabriz 5166-61647, Iran

2 Department of Mechanical Engineering, University of Maragheh, Maragheh 5518-18311, Iran improve the strength of the aluminum alloys $[4,6]$. However, new techniques have been recently developed to improve the properties of these materials. Therefore, the researchers have recently paid significant attention to the study of the aluminum alloys in order to produce ultra-fine grains (UFG) structure via novel techniques [7, 8].

The UFG materials can be produced with two approaches: up to down and down to up $[4,7,8]$. In the first method, the main purpose is to change the coarse-grain structure of the material and subsequently obtain a material with the nanostructure. In the second approach, a bulk material is produced by the arrangement of atoms with nanoscale components. The first approach has several advantages over the second one, which are as following: (1) The scale and the volume of the obtained samples are bigger, (2) there is not any trace of porosity or pollution in the material that can be attributed to the manufacturing process and (3) by using this method, it is feasible to process a wide range of materials, including metals and their alloys [8]. In the up-to-down approach, there are various ways that a series of them are in the category of 
introducing the mechanical work in the material. One of the main techniques of this group is the severe plastic deformation process. As a matter of fact, severe plastic deformation (SPD) is the most effective method to obtain ultra-fine grains in the materials. SPD process includes various techniques, meanwhile, some important methods are equal-channel angular pressing (ECAP) [9, 10], multidirectional forging (MDF) [7], accumulative roll bonding (ARB) [10] and high-pressure torsion (HPT) [6, 7]. Generally, for producing UFG materials by using the SPD methods, it is necessary to introduce a severe plastic strain that can produce the high density of the dislocations. Furthermore, it is crucial that the produced dislocations experience the recrystallization process in order to form an array of the grain boundaries [11, 12]. Ultra-fine grain (UFG) materials usually show more excellent mechanical and physical properties than the coarse-grain materials [11].

One of the newest methods of the severe plastic deformation processes is accumulative press bonding (APB). This process has been developed by Amirkhanlou et al. [13] for the first time, in order to produce $\mathrm{Al} / \mathrm{WCp}$ composites. In this newly developed field, there is not any other published work except above-mentioned work. The process has significant potential in the fabrication of materials with ultrafine grain size and even nanomaterials. Additionally, it can be properly used for joining of similar or dissimilar metals, in both hot and cold form. Another main advantage of this approach is its simplicity and low cost-since it can be performed without any expensive and special equipment in comparison with other SPD methods. That is why in this paper the feasibility of APB process for producing aluminum parts with very fine grains was investigated in various passes of the process by studying of mechanical and metallurgical properties.

APB process consists of the different stages, which are surface preparation, putting the strips on each other, pressing with thickness reduction of $50 \%$ and producing an integrated plate with the initial thickness. After these stages, the fabricated samples are cut from the longitudinal direction and the previous steps are applied to attain the desirable strain. Considering the fact that the thickness of the sheet is constant during the APB process, there is not any limitation on the amount of the strain that can be applied to the samples and it is viable to produce UFG and high-strength materials. The principal objective of this article is to investigate the influences of APB process and the number of passes on the mechanical and metallurgical properties of AA1100 alloy.

\section{Experimental}

At the present work, the sheets of AA1100 alloy were used as the test materials. Chemical composition and mechanical properties of the alloy are shown in Table 1. Aluminum sheets are cut in the dimension of $50 \mathrm{~mm} \times 50 \mathrm{~mm}$ $\times 1.5 \mathrm{~mm}$. After this stage, the samples are annealed for $2 \mathrm{~h}$ at $370{ }^{\circ} \mathrm{C}$ in an electrical furnace [14]. The image of the annealed microstructure of AA1100 alloy is illustrated in Fig. 1. According to the optical microscopy, the obtained average grain size for the annealed sample is $36 \mu \mathrm{m}$. As it can be seen in this figure, there is not any trace of the mechanical work on the samples and the grains are almost spherical in a way that the elongation cannot be observed in the longitudinal and transverse directions.

In order to form a satisfactory bonding between the strips in APB process, any contamination such as the grease and oxides should be removed from the surface of the sheets [15]. There are various methods for carrying out this process; however, the researchers have proposed that the best approach is degreasing the surface by scratch brushing [8]. First of all, two sheets are washed in an acetone bath in order to remove any contamination; then, the scratch brushing process, by a steel brush with wire diameter of $0.4 \mathrm{~mm}$, is performed to remove the oxide layers. After this process, two strips with thickness of $1.5 \mathrm{~mm}$ were put on each other from the brushed surfaces of the sheets, in a way that the total thickness would be $3 \mathrm{~mm}$. Then, they were put between the plates with hardened surface and the press bonding process is done with a 50\% reduction in the thickness so that the total thickness of two strips would be $1.5 \mathrm{~mm}$. After these stages, the press bonded strips are cut from the middle of the sheets and one side of the cut strips was cleaned and wire-brushed, and then again they are put on each other to begin the same press process again. These steps are repeated for six times in order to achieve a material with ultra-fine grain size. It is suggested that the time between the surface preparation and the press bonding should be less than $120 \mathrm{~s}$ in order to prevent the formation of the oxide films on the surfaces of the work piece [14]. The schematic illustration of the APB process is shown in Fig. 2.

To investigate the microstructure of the fabricated samples with APB method, an optical microscope was utilized. First of all, to perform the metallography, the obtained samples with the different numbers of passes are mounted and polished mechanically. The etching process of the polished samples is completed using electro-etch approach. Compositions of the etching solution are $5 \mathrm{ml}$ $\mathrm{HBF}_{4}$ and $200 \mathrm{ml}$ distilled water. Then, the prepared solution is poured in a container; thereafter, the cathode (stainless steel) and anode (APB sample) of an electric source $(20 \mathrm{~V})$ can be inserted in this container. The anode and cathode should be held into the solution for $10 \mathrm{~s}$, which is required for electro-etching. Subsequently and immediately, the optical microscopy of samples is prepared. Eventually, an optical microscope is utilized to record the microstructure of the fabricated samples. 
Table 1 Specification of the commercial pure (CP) aluminum strip used in this study

\begin{tabular}{|c|c|c|c|c|c|c|c|}
\hline Grade & Chemical composition (wt\%) & Temper & $\begin{array}{l}\text { Tensile strength } \\
(\mathrm{MPa})\end{array}$ & $\begin{array}{l}\text { Yield strength } \\
\text { (MPa) }\end{array}$ & $\begin{array}{l}\text { Elongation } \\
(\%)\end{array}$ & $\begin{array}{l}\text { Hardness } \\
\text { (HV) }\end{array}$ & $\begin{array}{l}\text { Grain size } \\
(\mu \mathrm{m})\end{array}$ \\
\hline AA 1100 & $\begin{array}{l}99.16 \mathrm{Al}, 0.17 \mathrm{Si}, 0.45 \mathrm{Fe}, 0.05 \mathrm{Cu} \text {, } \\
0.055 \text { others }\end{array}$ & 24 & 89.19 & 121.45 & 27.09 & 38 & 36 \\
\hline
\end{tabular}

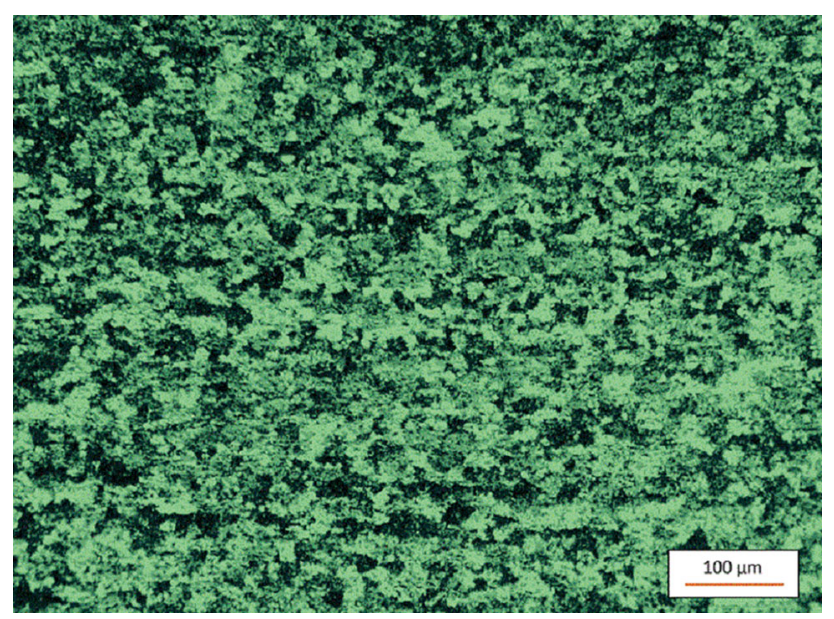

Fig. 1 Image of optical microscopy of the annealed AA1100 alloy

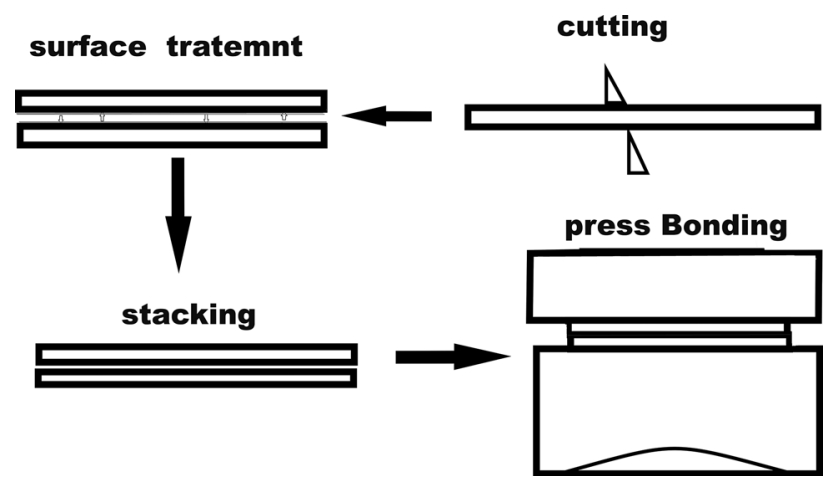

Fig. 2 Schematic illustration of APB process

It should be mentioned that one of the main key steps of metallography is the etching and polishing of sample surface, since it is very vulnerable to the formation of oxide layers. It is really challenging process to determine the grain size of the samples, especially in the last passes of the process, since the grains' size in these stages is very fine. Therefore, an image analyzer software was used in order to determine the approximate grain size of the samples. By using this software, the grain size of the samples was determined on several areas and then the average grain size was recorded.

The samples for tensile test were prepared according to ASTM E8/E8M standard [9] and the dimensions are shown in Fig. 3. The tensile test machine of the sample is zwick/

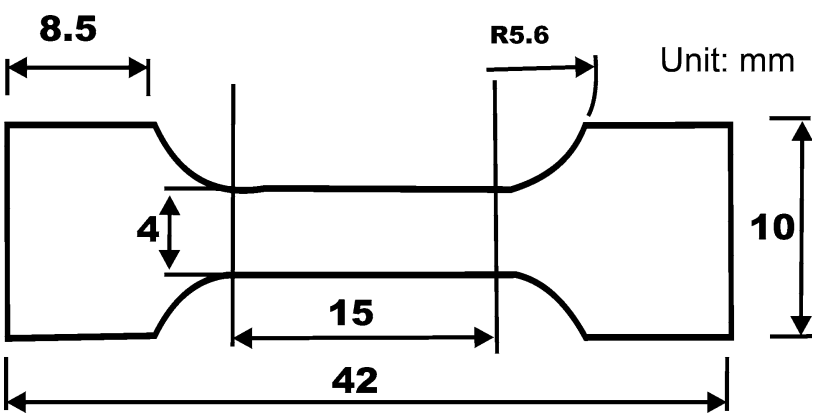

Fig. 3 Dimensions of the samples for tensile test

roell-Z010 with speed of $1 \mathrm{~mm} / \mathrm{min}$. Microhardness values of the samples were measured with $0.5 \mathrm{~N}$ load by M-400 G-G7-6363 machine according to the ASTM-E38411e1 standard [13]. According to this standard, seven tests were done on seven different locations of the samples. The average microhardness value was obtained [14]. In this test, the amount of the load was 50 gr and the duration was $10 \mathrm{~s}$.

Moreover, the obtained results from this novel approach were compared by other conventional and similar techniques. For drawing a comparison between this method and other techniques, the obtained results from ARP process, which is very similar to APB process, were utilized (results of Ref. [16]). In the published paper [16], commercially pure aluminum was used, which was processed via ARP with 6 passes. In the ARP method, the experiment was done in the ambient temperature and the raw sheet had been annealed in $370{ }^{\circ} \mathrm{C}$ for $2 \mathrm{~h}$ before starting the process.

\section{Results and Discussion}

\subsection{Microstructure}

The optical microscopy images of the longitudinal sections of the polished samples, which were not etched, are shown in Fig. 4. It can be seen that in the initial pass of the process, there is not a complete bonding among the layers, and in some areas, the discontinuity can be observed on the interface of two layers. It is due to the existence of the contamination and the oxide layers on the interface of these layers. In order to join two layers in the cold weld condition, it is crucial to have the sufficient amount of the 
applied forces to break the surface oxide layers and to provide the enough extrusion in both layers and subsequently to produce the formation of atom bonding and cold weld (Fig. 5) [15, 17].

The microstructures of the etched samples are shown in Fig. 6. The microstructural image of the samples fabricated with one pass is shown in Fig. 6a. As it can be seen, the grains become thinner along the longitudinal direction. In other words, the grains are stretched at this direction. The sizes of these grains are measured on different locations of the cross section, and the calculated average value is approximately $22 \mu \mathrm{m}$. After the third pass, the stretching phenomenon is more intense; however, there is not any trace of the grain crushing, and the average grain size is $15 \mu \mathrm{m}$. Nevertheless, after the fifth pass, besides the thinning effect in longitudinal direction, the crushing phenomenon can be clearly seen, and the average grain size is $1 \mu \mathrm{m}$ (Fig. 6c). Eventually, after sixth pass of the APB process, the crushing phenomenon is completely observable and the approximate average value of the grain size is $950 \mathrm{~nm}$ (Fig. 6d). It can be seen that with an increase in the number of passes, the size of grains goes down and this decrease in the size of the grains is surely

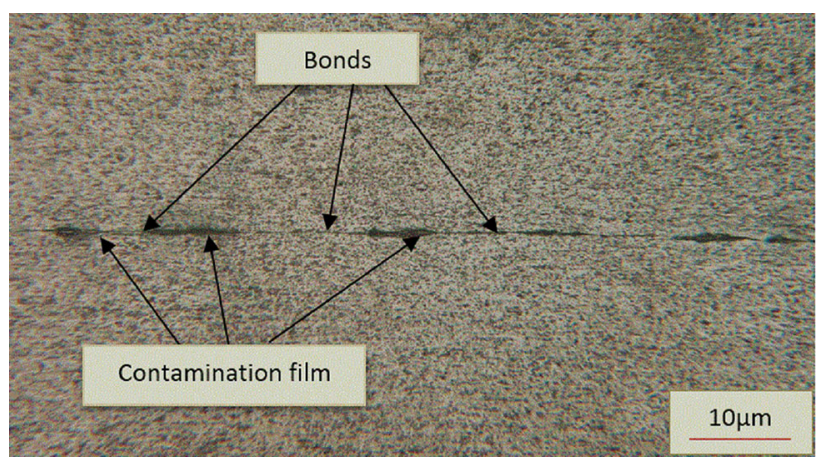

Fig. 5 Illustration of the mechanism of the surface film formation in the first pass of APB process

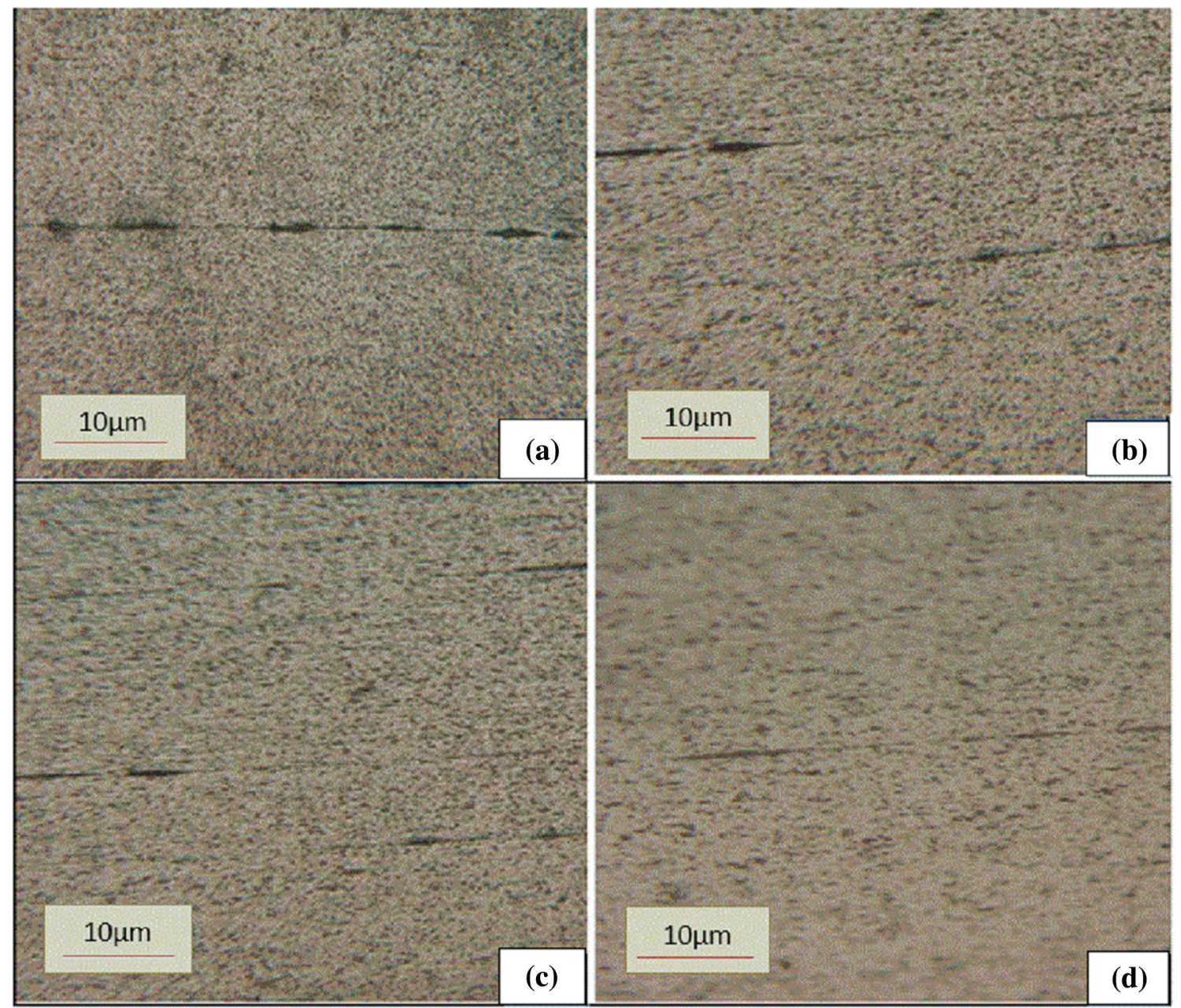

Fig. 4 Optical microscopy of the samples produced by APB process in $\times 10$ magnification: a the first pass, $\mathbf{b}$ the third pass, $\mathbf{c}$ the fifth pass, $\mathbf{d}$ the sixth pass 

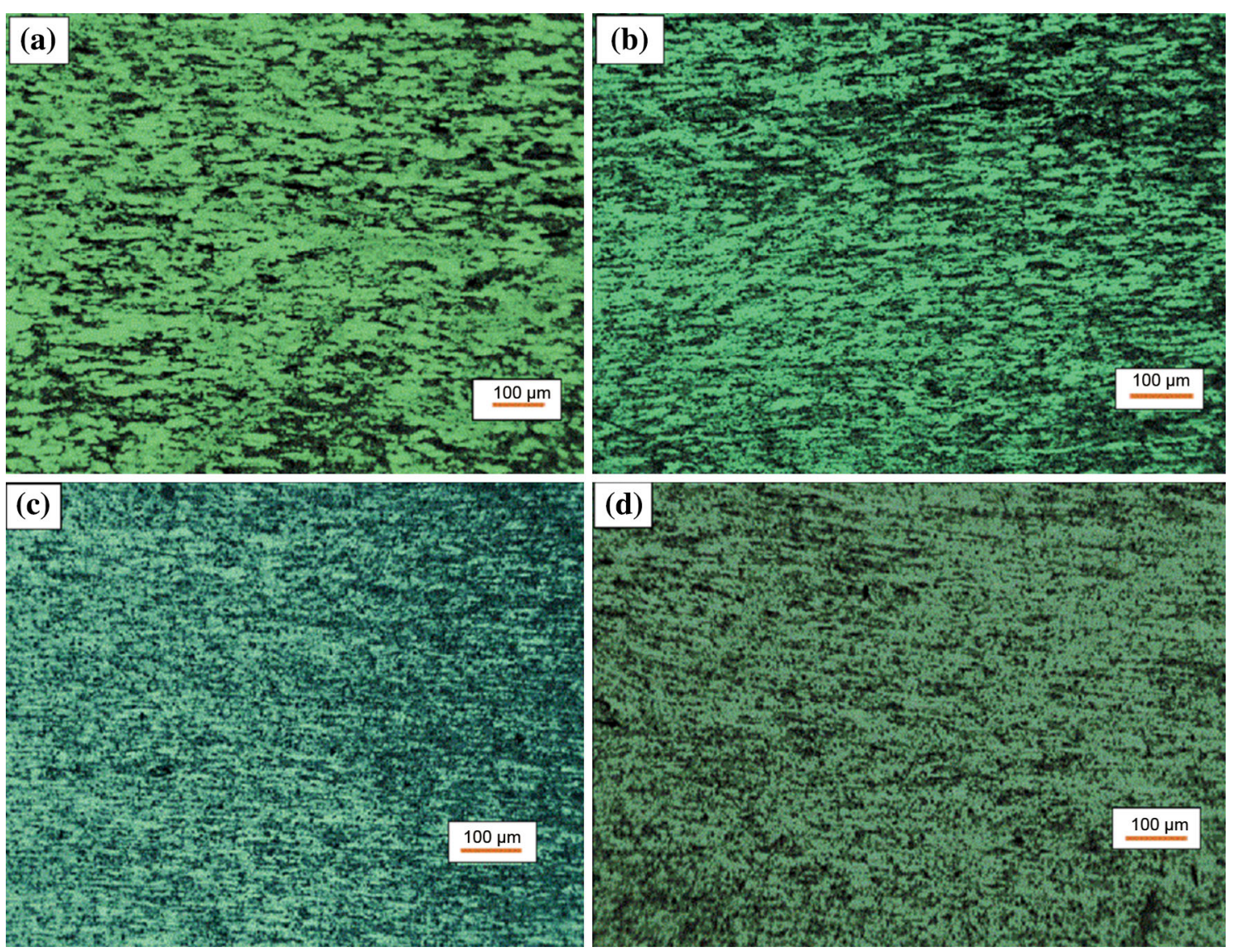

Fig. 6 Polarized optical microscopy of the cross section a the first pass, $\mathbf{b}$ the third pass, $\mathbf{c}$ the fifth pass, $\mathbf{d}$ the sixth pass

from the increase in the plastic deformation. Nonetheless, in the final passes, the local agglomeration of the dislocations and the angular difference in the matrix can result in the crushing effect and the formation of the grains with smaller sizes [18, 19]. Moreover, severe shear deformation is formed under the surface via the friction between the press and the sheets. This severely deformed area can spread into the deeper parts of the sheets as the pass increases, leading to the ultimate strain value. Therefore, after some passes of the process, the whole thickness of the sheet may be affected by severe shear strain $[13,20]$.

\subsection{Mechanical Properties}

The results of the tensile tests show that with the increase in the number of passes of APB process, the yield strength can go up (Fig. 7). The yield strength of AA1100 raw material is $89 \mathrm{MPa}$; however, this value can reach $264 \mathrm{MPa}$ in the samples processed with six passes, which clearly suggests an almost three times rise in the value of the yield strength. It has been reported that the strength variations in the severely deformed materials are governed by the two main strengthening mechanisms: grain

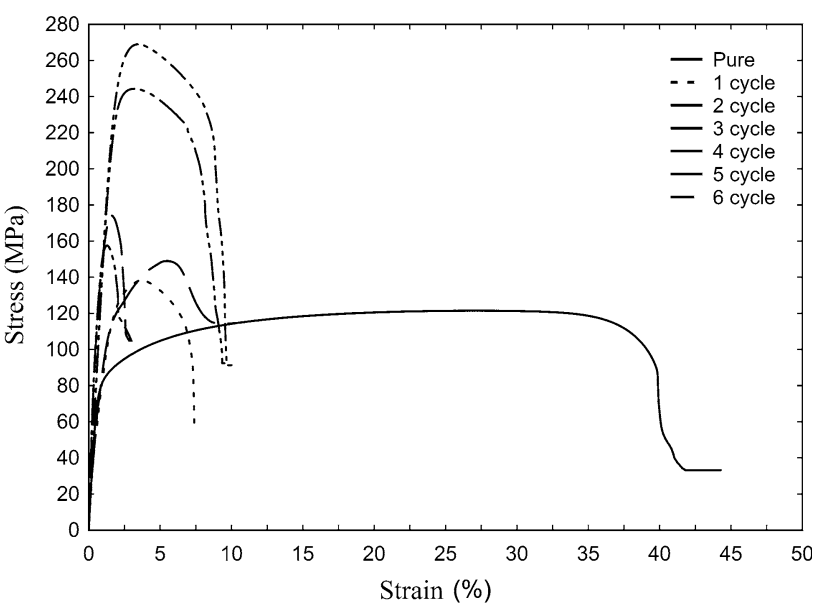

Fig. 7 Stress-strain curve of fabricated samples with different numbers of passes of the APB process

refinement and strain hardening [13, 21, 22]. (1) Strain hardening or dislocation strengthening: By increasing the number of APB passes, plastic deformation of an alloy increases and more dislocations are generated. Thus, the dislocations are pinned together and cause strengthening of the alloy. (2) Grain refinement strengthening: Regarding 
the Hall-Patch equation, by decreasing the grain size, the strength of the metal increases, and this technique is one of the conventional mechanisms used for the strengthening of metals $[22,23]$. Therefore, with the increase in the number of passes, the yield strength can increase and the elongation can decrease (Fig. 8). Microstructural investigation reveals that after the sixth pass, the size of the grain can decrease from $36 \mu \mathrm{m}$ to $950 \mathrm{~nm}$. Furthermore, the relationship between the size of the grains and the increase in the strength can be justified by the Hall-Patch equation [4, 24].

$\sigma_{y}=\sigma_{i}+\frac{K_{y}}{\sqrt{ } D}$

In this equation, $\sigma_{y}$ is yield strength, $\sigma_{i}$ is yield strength before the performing of refining process, $K_{y}$ is a constant which depends on the material and $D$ is the grain size.

According to the diagram of Fig. 8, the percentage elongation is initially decreased. In fact, this abrupt reduction in elongation after the initial stages of the APB

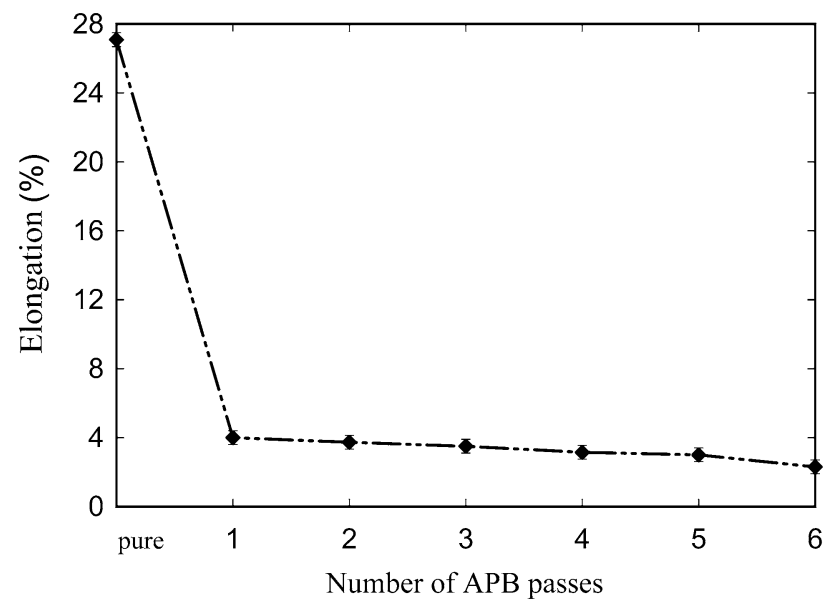

Fig. 8 Diagram of percentage elongation of AA1100 alloy fabricated by different passes of APB process

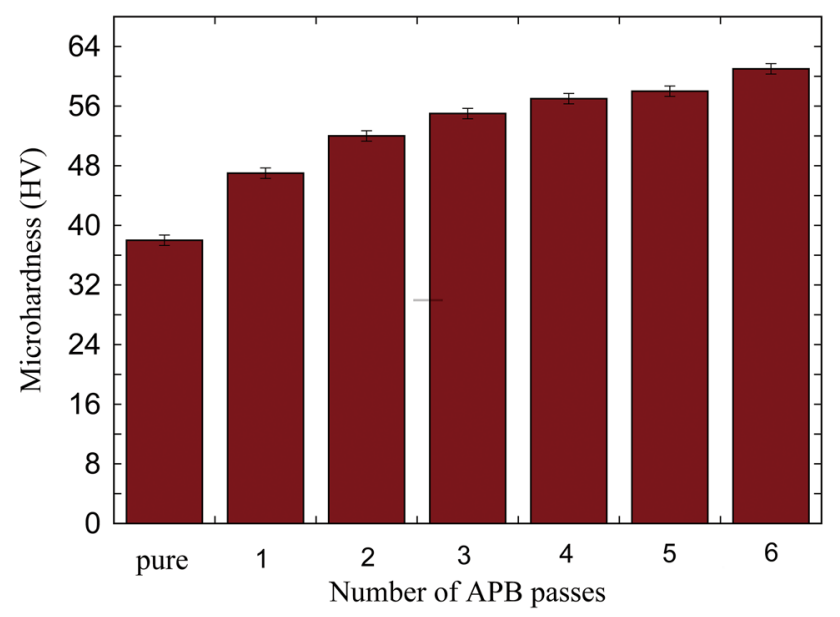

Fig. 9 Variation of the hardness with the passes of the APB process process (after $50 \%$ of reduction in the thickness) can be described with the decrease in the dislocation movements, with the reduction in the rate of the strain hardening and the number of shear bonds. The reduction in the flexibility is usually affected by the work hardening of the material [25]. Generally, the materials with very fine structure show lower amounts of deformation in comparison with the materials with coarse grains due to the lack of dislocations activity or the insufficient rate of the strain hardening [25-27]. The previous investigations showed that with the reduction in the grain size, the rate of the strain hardening is not increased, even can be decreased too [25, 26].

The results of the microhardness test are shown in Fig. 9. It can be seen that the microhardness value can be increased by a rise in the number of APB passes, and this value is increased from 38 to $61 \mathrm{HV}$ after 6 passes. The rapid and considerable amount of the rise in the

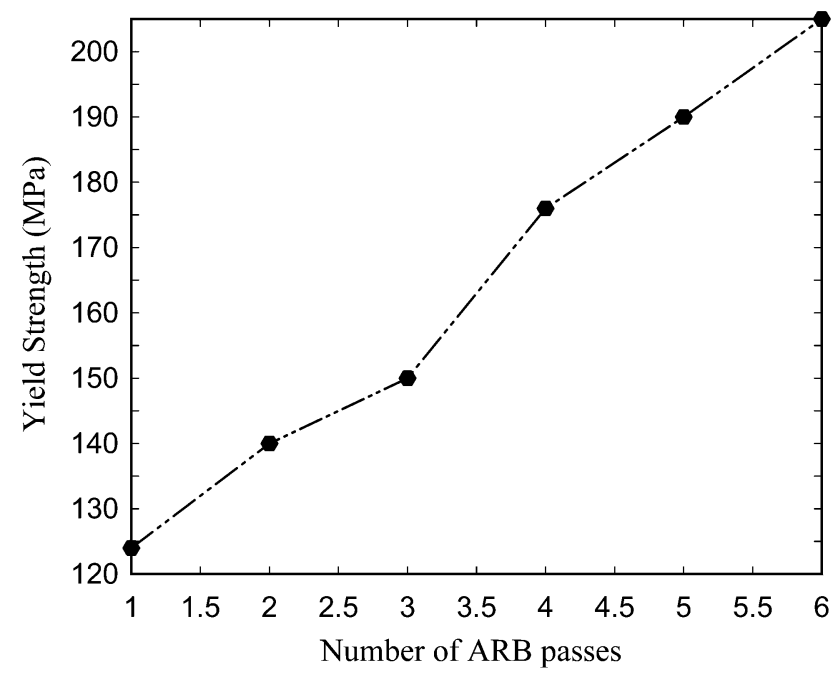

Fig. 10 Yield strength of pure aluminum fabricated via ARB in various passes of process

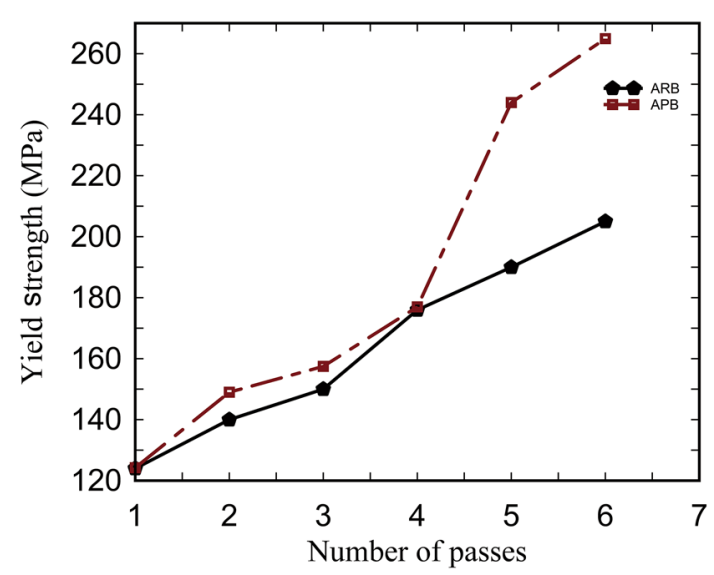

Fig. 11 Comparison of yield strength of AA1100 fabricated via APB and ARB in the first and last passes of both processes 
microhardness value in the primary stages of the process can be contributed to the strain hardening effect and increase in the dislocation density [28]. However, in the final passes, the dominant effect for increasing the hardness is the recrystallization, which is more effective than the strain hardening, and as a result the rate of layer hardening can be decreased [22, 28-30].

The results of tensile tests of processed samples in various passes are presented in Fig. 10 [16] and the comparison of these two processes is presented in Fig. 11. It can be seen, with an increase in the number of passes, the ultimate tensile strength can be increased; however, the rise of the strength in APB process, especially in final passes, is much more than that in ARB process. In other words, although the maximum obtained strength for ARB process is $205 \mathrm{MPa}$ [16], the ultimate tensile strength of AA1100 alloy after the sixth pass of APB is approximately $265 \mathrm{MPa}$. Therefore, in this novel process, the increase in the strength is 1.3 times much more than that of the conventional one, which is an outstanding achievement.

\section{Conclusions}

1. With increasing the number of passes of APB process, the quality of the joint can be improved.

2. According to the microstructural investigation, very tiny grains with the approximate values of $950 \mathrm{~nm}$ were produced after six passes of the APB process.

3. The yield strength of the fabricated samples increased by the rise in the number of APB passes and reached the maximum value of $264 \mathrm{MPa}$ at the end of the sixth pass, which was 3 times higher than that obtained for the raw and annealed AA1100 alloy.

4. With the increase in the number of passes of the APB process, the percentage elongation was decreased.

5. The microhardness test results showed that a rise in the number of passes can increase the microhardness value of the alloy reaching $61 \mathrm{HV}$ at the end of the sixth pass.

\section{References}

[1] S.S. Li, J. Chen, C. Chen, D.Zeng Xia, Acta Metall. Sin. (Engl. Lett.) 28, 678 (2015)

[2] A. Elrefaey, N.G. Ross, Acta Metall. Sin. (Engl. Lett.) 28, 715 (2015)
[3] Z.Y. Ye, D.X. Liu, M. Yuan, X.M. Zhang, Z. Yang, M.X. Lei, Acta Metall. Sin. (Engl. Lett.) 28, 608 (2015)

[4] I. Sabirov, M.Y. Murashkin, R.Z. Valiev, Mater. Sci. Eng. A 560, 1 (2013)

[5] W.R. Osório, L.C. Peixoto, L.R. Garcia, A. Garcia, Acta Metall. Sin. (Engl. Lett.) 22, 241 (2009)

[6] A. Azushimaa, R. Koppb, A. Korhonenc, D.Y. Yangd, F. Micarie, G.D. Lahotif, P. Grocheg, J. Yanagimotoh, N. Tsujii, A. Rosochowskij, A. Yanagidaa, CIRP Ann.Manuf. Technol. 57, 716 (2008)

[7] R.Z. Valiev, Y. Estrin, Z. Horita, T.G. Langdon, M.J. Zehetbauer, Y. Zhu, JOM 58, 33 (2006)

[8] P.B. Prangnell, J.R. Bowen, P.J. Apps, Mater. Sci. Eng. A 375, 178 (2004)

[9] R.Z. Valiev, T.G. Langdon, Prog. Mater Sci. 51, 881 (2006)

[10] Z.M. Zhang, C.J. Xu, J.C. Wang, H.Z. Liu, Acta Metall. Sin. (Engl. Lett.) 19, 223 (2006)

[11] R.Z. Valiev, N.A. Krasilnikov, N.K. Tsenev, Mater. Sci. Eng. A 137, 35 (1991)

[12] R.Z. Valiev, Mater. Sci. Eng. A 234, 59 (1997)

[13] S. Amirkhanlou, M. Ketabchi, N. Parvin, S. Khorsand, R. Bahrami, Mater. Des. 51, 367 (2013)

[14] M.R. Toroghinejad, R. Jamaati, J. Dutkiewicz, J.A. Szpunar, Mater. Des. 51, 274 (2013)

[15] M. Eizadjou, H.D. Manesh, K. Janghorban, Mater. Des. 30, 4156 (2009)

[16] M. Raei, M.R. Toroghinejad, R. Jamaati, J.A. Szpunar, Mater. Sci. Eng. A 527, 7068 (2010)

[17] H.A. Mohamed, J. Washburn, Weld. J. 54, 302 (1975)

[18] N. Tsuji, T. Toyoda, Y. Minamino, Y. Koizumi, T. Yamane, M. Komatsu, M. Kiritani, Mater. Sci. Eng. A 350, 108 (2003)

[19] A. Rezaee-Bazzaz, S. Ahmadian, H. Reihani, Mater. Des. 32(8), $4580(2011)$

[20] S.H. Lee, Y. Saito, N. Tsuji, H. Utsunomiya, T. Sakai, Scr. Mater. 46, 281 (2002)

[21] X. Huang, N. Tsuji, N. Hansen, Y. Minamino, Mater. Sci. Eng. A 340, 265 (2003)

[22] N. Wang, Z.R. Wang, K.T. Aust, U. Erb, Acta Metall. Mater. 43, 519 (1995)

[23] H. Pirgazi, A. Akbarzadeh, R. Petrov, L. Kestens, Mater. Sci. Eng. A 497, 132 (2008)

[24] Y. Saito, N. Tsuji, H. Utsunomiya, T. Sakai, R.G. Hong, Scr. Mater. 39, 1221 (1998)

[25] D.G. Morris, Strength and Ductility of Nanocrystalline Materials: What do Really Understand? in Proceeding of the 22th Riso International Symposium on Material Science: Science of Metastable and Nanocrystalline Alloys Structure, Properties and Modeling. Riso National Laboratory, Roskilde, Denmark, September 3-7, 2001

[26] N. Tsuji, Y. Ito, Y. Saito, Y. Minamino, Scr. Mater. 47, 893 (2002)

[27] Y.M. Wang, E. Ma, Acta Metall. 52, 1699 (2004)

[28] J. Gubicza, N.Q. Chinh, T. Csanádi, T.G. Longdon, T. Ungár, Mater. Sci. Eng. A 462, 86 (2007)

[29] R. Anthony, F.J. Humphreys, G.S. Rohrer, M. Hatherly, Recrystallization and Related Annealing Phenomena (Elsevier, Amsterdam, 2004)

[30] D.A. Hughes, N. Hansen, Acta Mater. 45, 3871 (1997) 